\title{
Erzurum'dan Toplanan Kulaklı Orman Baykuşu (Asio otus) Peletlerinde Memeli Hayvan Türleri
}

\author{
Alaettin KAYA ${ }^{1}$, Yüksel COŞKUN ${ }^{1 *}$ \\ ${ }^{1}$ Dicle Üniversitesi, Fen Fakültesi, Biyoloji Bölümü, 21280, Diyarbakır
}

\section{Özet}

Erzurum'da toplanmış, Kulaklı Orman Baykuşu (Asio otus)'na ait 134 pelet içerisinde 205 memeli hayvan kalıntısı incelenmiştir. Her pelette ortalama 1,42 memeli hayvan kalıntısı bulunmuştur. Rodentia ordosundan Microtus guentheri, Microtus sp., Cricetulus migratorius, Meriones sp., Apodemus sp ve Mesocricetus brandti türlerine ait kalıntılar tespit edilmiştir. Microtus guentheri $\%$ 68,5 oran ile en sık görülen memeli türü olduğu tespit edilmiştir.

Anahtar kelimeler: Asio otus, Rodentia, Mammals, Baykuş Peleti, Türkiye.

\section{The Remains of Small Mammals in the Eagle Owl (Asio otus) Pellets from Erzurum Province}

\begin{abstract}
A total 205 remains found in 134 pellets of the Long-eared owl (Asio otus) collected from Erzurum were examined. 1,42 mammalian items in average found in each pellet. The remains of the members of the order Rodentia were determined to be of Microtus guentheri, Microtus sp., Cricetulus migratorius, Meriones sp., Apodemus sp and Mesocricetus brandti. Microtus guentheri was found small mammal species with a ratio of $68,5 \%$ in the pellets.
\end{abstract}

Keywords: Asio otus, Rodentia, Mammals, Owl Pellets, Turkey.

\section{Giriş}

Kulaklı orman baykuşu, Asio otus, ibreli ormanlar, seyrek ağaçlı açık araziler, kırlar, bataklıklar ve kumullarda yaşayan yaygın bir baykuş türüdür [1]. Baykuşlar bütün halde yuttukları besinleri içerisinde sindirilemeyen kafatası, diş, kemik, tüy ve post gibi yapıları içeren artıkları kusarlar. Çoğunlukla gri renkli olan bu kusmuk topları pelet olarak adlandırılır.

Son yıllarda, memeli hayvan türlerinin yaşadıkları alanların tespit edilmesinde ve bir bölgenin memeli çeşitliliğinin belirlenmesinde, baykuş gibi birçok yırtıcı kuşun pelet analizi çalışmaları yaygın olarak kullanılmaktadır [2-4]. Türkiye'de bu tür çalışmalar sınırlı sayıdadır. Steiner ve Vauk [5] Beyşehir Gölü çevresinden Asio otus; Hoppe [6] Antakya çevresinden Tyto alba; Kasparek [7- 8] Sultan sazlığından ve Bafa gölü'nden; Morgan [9] Bubo bubo'ya ait peletleri; Kock [10] Bursa çevresinden Strix aluco; Seçkin ve Coşkun [11-12] Diyarbakır'dan Asio otus; Seçkin ve ark. [13] Diyarbakır Bismil'den Bubo bubo; Hızal [14] Konya- Karapınar'dan Asio otus; Kaya ve Coşkun [15] Nevşehir'den Athene noctua, Tyto alba ve Bubo bubo türlerinin ve Göçer [16] Denizli'den Asio otus peletlerini inceleyerek memeli hayvan türüne ait kalıntılar tespit etmişlerdir.

$\mathrm{Bu}$ çalışmada Erzurum ilinden toplanmış kulaklı orman baykuşu (Asio otus)'na ait peletlerdeki memeli hayvan türlerinin tespiti amaçlanmıştır. 


\section{Materyal ve Metot}

Kulaklı orman baykuşu (Asio otus)'na ait 134 pelet örneği Erzurum Atatürk Üniversitesi Kampus alanı ( $34^{\circ} 54^{\prime} \mathrm{K}$ ve $\left.41^{\circ} 14^{\prime} \mathrm{D}\right)$ içindeki çam ağaçları diplerinden toplanmıştır (Şekil 1).

Pelet analizleri standart yöntemlere [2-3] uygun olarak yapılmıştır. Sterilizasyon amacıyla her pelet önce birkaç dakika alkol içinde bekletilmiştir. Daha sonra pelet su içine alınarak iyice yumuşaması sağlanmış, ardından her pelet iğne ve pens yardımı ile didiklenerek açılmıştır. Her pelet içeriği; kafatası, alt çene ve diğer kemikler analiz için ayrı kutulara alınmıştır. Kalıntıların hangi türlere ait olduğunu ayırt etmek için Ellerman [17-18], Ognev [19], Osborn [20], Vinogradov ve Argiropulo [21],

Krystufek ve Vohralik [22]'in tür tayin anahtarları kullanılmıştır. Peletler 2011 yılında toplanmış olup Dicle Üniversitesi Fen Fakültesi Biyoloji Bölümünde korunmaktadır.

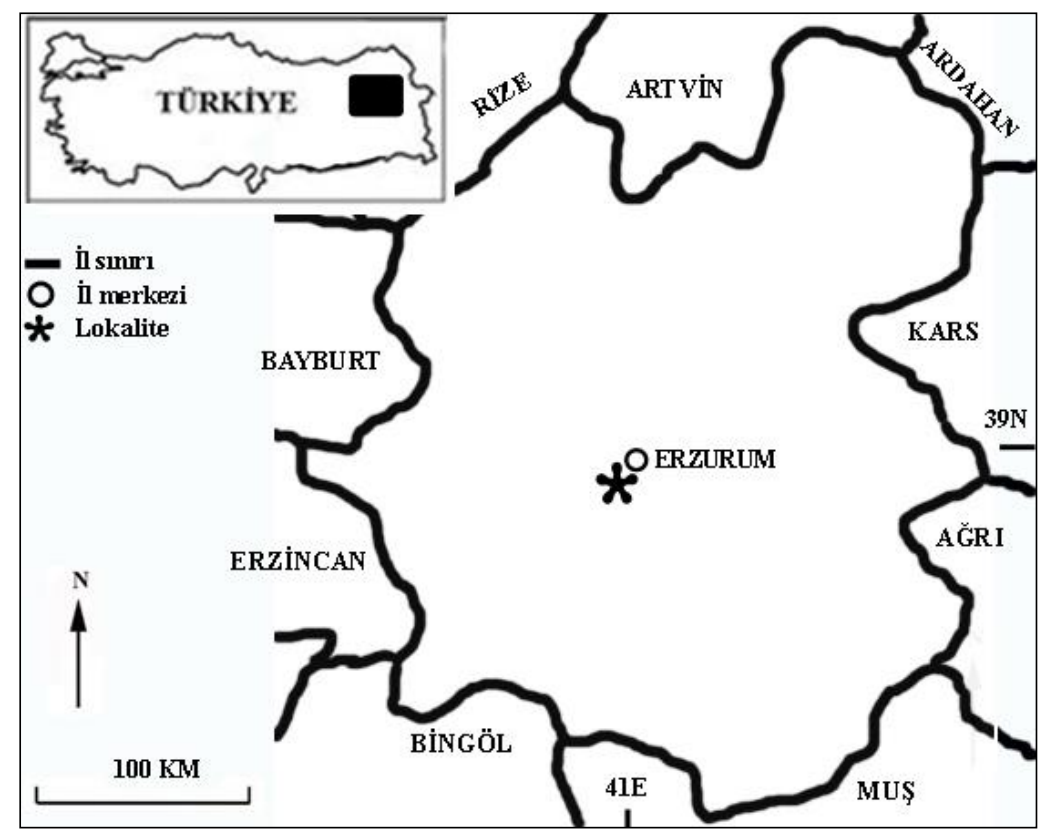

Şekil 1. Materyalin toplandığı lokalite

\section{Bulgular ve Tartışma}

Peletlerin içeriklerinin büyük kısmını küçük memeli hayvanların kalıntılarının oluşturduğu görülmüştür. 134 pelet içerisinde 205 memeli hayvan kalıntısı ayırt edilmiştir. Genel olarak her pelette bir, iki veya üç hayvan kalıntısı bulunurken, maksimum beş (ortalama 1,42) hayvan kalıntısına rastlanmıştır. Toplanan peletlerden altmış dokuz tanesinde bir; otuz beş tanesinde iki; on dört tanesinde üç; bir tanesinde dört; bir tanesinde beş adet hayvan kalıntısı ( 5 adet Microtus guentheri) bulunmuştur. Kuş ve böceklere ait kalıntıların tüm kalıntılar içinde sırasıyla $\% 5,9$ ve $\% 0,5$ oranda olduğu görülmüştür.

Rodentia ordosunun altı türüne (Microtus guentheri, Microtus sp., Cricetulus migratorius, Meriones sp., Apodemus sp., Mesocricetus brandti) ait kalıntılar tespit edilmiştir (Şekil 2).

Memelilerin kalıntıların hemen hepsini (\% 93,6); Microtinelerin ise memeli kalıntılarının çoğunluğunu (\% 92,2) meydana getirdiği gözlenmiştir. Microtus guentheri \% 68,5 oran ile kalıntılarda baskın olurken, Microtus sp. \% 24,4 oranı ile en sık görülen ikinci, Mesocricetus brandti \% 3,9 oranı ile s1k bulunan üçüncü tür olmuştur. Meriones sp., Apodemus sp. ve Cricetulus migratorius kalıntılar içinde daha az yoğunluklarda tespit edilmiştir. 


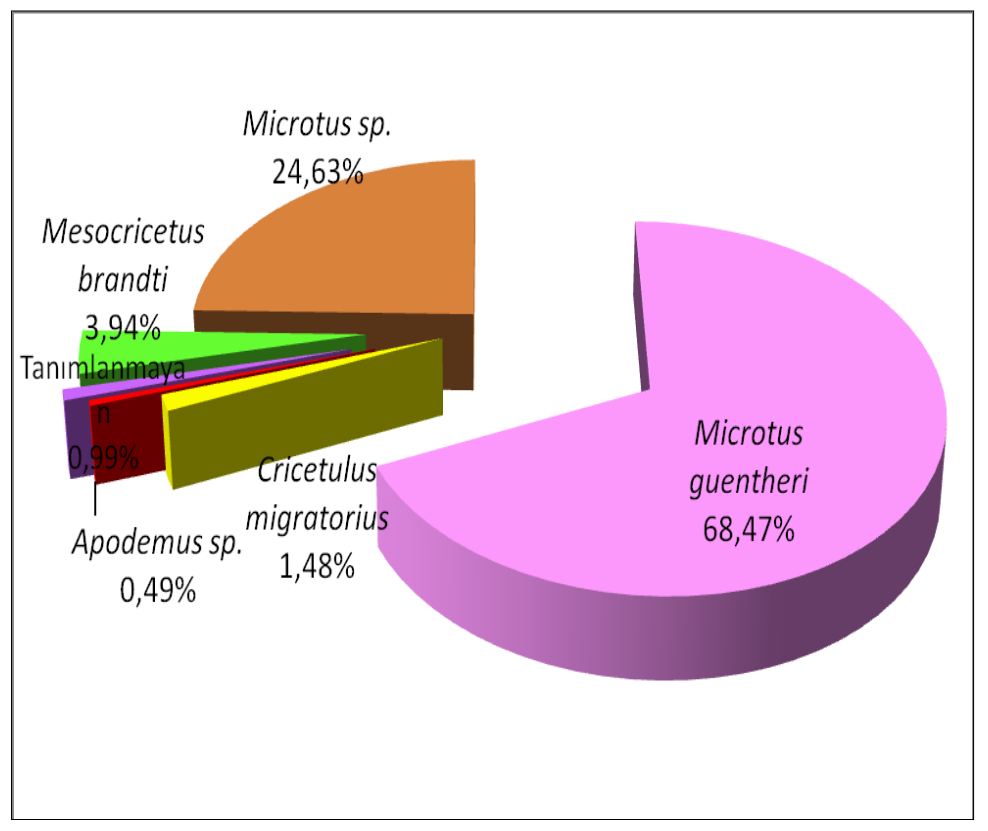

Şekil 2. Peletlerdeki memeli türlerinin oransal dağılımı

\section{Sonuç ve Öneriler}

Diyarbakır'dan Asio otus peletlerinde, her pelette genel olarak bir veya iki; bir pelette maksimum dört memeli hayvan kalıntısı bulunmuştur [11-12]. Shao ve Liu [4], Çin'den aldıkları Asio otus peletlerinde rodentlerin \% 98,02 oranla dominant olduğunu ve bir peletteki birey sayısının bir ile üç arasında değiştiğini kaydetmişlerdir. Seçkin [23] Güneydoğu Anadolu Bölgesi'nden çeşitli baykuşlara ait pelet kalıntılarında memelilerden rodentlerin \% 94,5 oranıyla en fazla rastlanan grup olduğunu; Microtineler ve Muridlerin insan aktivitelerinden çok etkilenmedikleri için pelet kalıntıları içinde yoğun olarak tespit edildiğini kaydetmiştir.

Seçkin ve Coşkun [11-12] Asio otus peletlerinde Microtus guentheri'nin en fazla orana $(\% 71,3)$ sahip olduğunu kaydetmişlerdir.

Erzurum kalıntılarında Microtus guentheri'nin yoğunluğunun yüksek olduğu, hatta Microtinelerin memeli kalıntılarının çoğunluğunu meydana getirdiği, Cricetulus migratorius ve Apodemus sp. türlerinin yoğunluklarının az olduğu, yani bölgedeki canlı yoğunluğunun avlanan canlı türünü ve sayısını etkilediği görülmüştür.

\section{Kaynaklar}

1. Heinzel H., Fitter R., Parslow J. 1995. Türkiye ve Avrupa'nın Kuşları. Türkiye Doğal Hayatı Koruma Derneği, 384s. İstanbul.

2. Amr Z. S., Al-Melhim W. N., Yousef A. 1997. Mammals Remains from Pellets of the Eagle Owl, from Azraq Nature Reserve, Jordan, Zoology in the Middle East, 14: 5-10.

3. Obuch J. 1994. Diet of Tawny Owl in Selected Regions of Bohemia and Moravia, Sylvia, 30: 7785.

4. Shao M., Liu N. 2006. The Diet of the Long-eared Owls in the Desert of Northwest China, Journal of Arid Environments, 65: 673-676. 
5. Steiner H.M., Vauk G. 1966. Säugetiere aus dem Beyşehir-Gebiet (Konya, Kleinasien), Zoologische Anzeiger, 176: 97-102.

6. Hoppe N. 1986. Pellet Contents of the Barn Owl, Near Samandağ, Turkey, Zoology in the Middle East, 1: 29-31.

7. Kasparek M. 1985. Die Sultanssümpfe: Naturgeschichte eines Vogelparadieses in Anatolien. 156s. Heidelberg.

8. Kasparek M. 1988. Bafasee: Natur und Geschichte in der türkischgen Ägäis. 176s. Heidelberg,

9. Morgan D. 1983. An Analysis of Some Eagle Owl Pellets from Turkey, Sandgrouse, 5: 105-106.

10. Kock D. 1990. Notes on Mammals (Insectivora, Rodentia) taken by the Tawny Owl in NW Turkey, Zoology in the Middle East, 4: 5-9.

11. Seçkin S., Coşkun Y. 2005. Small Mammals in the diet of the Long-eared Owl from Diyarbakır, Turkey, Zoology in the Middle East, 35: 102-103.

12. Seçkin S., Coşkun Y. 2006. Mammalian Remains in the Pellets of the Long-eared Owls in Diyarbakır Province, Turkish Journal of Zoology, 30: 271-278.

13. Seçkin S., Kaya A., Coşkun Y. 2012. Başaklı Köyü (Diyarbakır-Bismil) Civarında Yaşayan Puhu (Bubo bubo)'ların Peletlerindeki Küçük Memelilerin Dağılımı, Cumhuriyet Üniversitesi Fen Bilimleri Dergisi, 33 (1): 34-42.

14. Hizal E. 2013. Diet of the Long-eared Owl, Asio otus, in Central Anatolia (Aves: Strigidae), Zoology in the Middle East, 59: 118-122.

15. Kaya A. Coşkun Y. 2014. Nevşehir'de Baykuş Peletlerindeki Memeli Hayvan Kalıntılarının Dağılımı, Nevşehir Bilim ve Teknoloji Dergisi, 3: 39-44.

16. Göçer E. 2016. Diet of a Nesting Pair of Long-eared Owls, Asio Otus, in an Urban Environment in Southwestern Turkey (Aves: Strigidae), Zoology in the Middle East, 62: 1-4.

17. Ellerman J.R. 1940. Key to the Rodents of South West Asia, Proc. Zool. Soc. Lond., 118: 785-792.

18. Ellerman J.R. 1941. The families and genera of living rodents. Vol. 2. Family: Muridae. British Museum Nat. Hist., 690s. London.

19. Ognev S.I. 1947. Mammals of the USSR and Adjacent Countries. Rodents, Vol.5, 809s.

20. Osborn D.J. 1962. Rodents of the Subfamily Microtinae from Turkey, Journal Mammalogy, 43: 515-529.

21. Vinogradov B.S., Argiropulo A.I., 1968. Fauna of the USSR. Mammals. "Key to rodents" Zoological Institute of the Academy of Science of the U.S.S.R. New series No: 29, IPST, 1968 241s Jerusalem.

22. Kryštüfek B., Vohralik V. 2009. Mammals of Turkey and Cyprus. Rodentia II: Cricetinae, Muridae, Spalacidae, Calomyscidae, Capromyidae, Hystricidae, Castoridae. Knjižnica Annales Majora, Koper 140s.

23. Seçkin S. 2009. Güneydoğu Anadolu Bölgesi Yırtıcı Kuş Peletlerindeki Küçük Memeli Hayvan Kalıntılarının Analizi. Dicle Üniversitesi, Fen Bilimleri Enstitüsü, Biyoloji Anabilim Dalı, Doktora Tezi, 140s, Diyarbakır. 